\title{
O PRAZER DA LEITURA EM FACUNDO
}

\author{
FACUNDO OU CIVILIZAÇã̃o E BARBÁRIE \\ De Domingo Faustino Sarmiento. Trad. e notas de Sérgio Alcides; prólogo de Ricardo Piglia; posfácio de \\ Francisco Foot Hardman. São Paulo: Cosac\&Naify, 2010.508 pp.
}

LAURA JANINA HOSIASSON

Do tempo que édepois, antes, agora, Sarmiento, o sonhador, continua nos sonhando.

Borges, "Sarmiento", O outro o mesmo

A leitura deste livro - em tradução cuidadosa de Sérgio Alcides confirma com espantosa evidência o fato de estarmos no século XXI ainda fincados de modo visceral no século XIX. Embora nossas convicções nacionalistas distem muito de ser as mesmas de Sarmiento e seus preconceitos raciais sejam intoleráveis para nós, ainda que seus prognósticos políticos soem ingênuos para o leitor latino-americano no presente, reconhecemos como nossas as contradições, os paradoxos, as ambivalências que marcam o discurso deste narrador que perscruta o mundo ao redor à procura do sentido de sua história. Sua perspectiva diante dos acontecimentos que narra nos atrai pela capacidade de enxergar a complexidade que há por trás do fato aparentemente simples. Para além de sua visão de mundo cindida em dois, um mundo que se debate entre as forças civilizadas vindas da Europa e a barbárie indígena e de lastro colonial, entre "os últimos progressos do espírito humano e os rudimentos da vida selvagem, entre as cidades populosas e as matas sombrias" (p.53), apesar dessa visão tributária decerto do romantismo de sua época, reconhecemos a desenvoltura de sua prosa e a forma como ele liga coisas que pareciam distantes e as atrela ao núcleo principal de seu argumento.

É preciso destacar, nesse sentido, o prazer da leitura desde os primeiros parágrafos. Escrito "de uma sentada só”, em não mais de dois meses - entre maio e junho de 1845 - , para ser publicado como folhetim no jornal chileno El Progreso, sua prosa viva, ágil e imaginosa embala o leitor num ritmo que nunca esmorece. Para falar de contingências da política internacional, Sarmiento lança mão de símiles e 
perífrases que dariam água na boca a qualquer um de nossos comentaristas atuais. Na sua visão, o mundo possui convergências inusitadas e paralelismos que podem ligar as rotações dos astros no firmamento às reviravoltas dos regimes autoritários aqui na terra. Sua perspectiva global dos acontecimentos internacionais lhe permite aludir às vicissitudes, aos processos histórico-culturais, à política ou à economia da Itália, da Polônia ou do Paraguai para falar da Argentina. Por outro lado, sua concepção do mundo asiático e oriental, marcada pelo exotismo, parece saída dos livros de Marco Polo e são recorrentes as alusões a "lembranças imaginárias" desse mundo excêntrico, devasso, desorganizado, atrasado, bárbaro enfim, para se referir às mazelas da situação argentina.

Em primeiro lugar, e sem nunca sair do espectro de seu horizonte, está o "Eu" do exímio narrador, figura que se insinua e já se define nas cenas descritas na "Advertência do autor", quando começa por nos alertar sobre os erros circunstanciais e as "inexatidões", derivados da situação de exílio em que se encontrava², obrigado a apelar para "as próprias reminiscências". Exemplo emblemático é a célebre citação ("on ne tue point les idées") que nessa mesma "Advertência", ele atribui a Fortoul: Paul Groussac a remeteria ao conde Volney, mas críticos recentes afirmam ser invenção dele próprio e Ricardo Piglia (no prólogo a esta edição), de Diderot 3 ! O mesmo ocorre com as epígrafes que inauguram cada capítulo, em sua maioria inexatas, incompletas e mal atribuídas. Mas isso está longe de significar motivo de preocupação para ele, que as assume como sinal de espontaneidade e de transparência, preferindo não retocar nada para não desaparecerem do livro "sua fisionomia primitiva e a audácia louçã e voluntariosa de sua concepção mal disciplinada", como ele mesmo declara em carta a Valentín Alsina, no momento da segunda edição da obra em $1851^{4}$. Nessa atitude já se mostra um tipo de narrador que se assume como leitor e intérprete ele também e que, adiantando-se em várias décadas, aponta para aquilo que Marcel Proust irá formular num pequeno e precioso texto "Sobre a leitura": a relação livre que o escritor poderia estabelecer com os documentos e livros que cita e a partir dos quais constrói sua obra5. Podemos pensar também que aqui reside uma das matrizes da relação libérrima e lúdica que se estabelece nas narrativas de Jorge Luis Borges com as fontes e as citações bibliográficas. Borges fará disso um procedimento estético.

O narrador de Facundo sente-se duplamente livre: de um lado, num território neutro, como o que ele encontra no seu exílio chileno, para dizer e escrever o que pensa, sem risco de vida; e de outro, sente-se livre e já maduro para elaborar um estudo capaz de aglutinar de modo magistral um enorme leque de gêneros e estilos, através dos quais perambula com absoluta soltura.

\begin{abstract}
[1] Um "Eu" megalomaníaco e delirante que valeu a Sarmiento o apelido de "Dom Eu".

[2] Em 1840, Sarmiento tinha sido deportado para o Chile pelo então governador de San Juan e partidário de Rosas, Nazario Benavides.
\end{abstract}

[3] Piglia fez do assunto matéria literária do seu primeiro romance, Respiração artificial (1980), no qual os personagens Renzi e Marconi discutem longamente sobre a citação apócrifa que abre Facundo.

[4] Esta carta encontra-se no "Apêndice" da edição aqui resenhada.

[5] Proust, Marcel. Sobre a leitura [1905]. Trad. Carlos Vogt. Campinas, SP: Pontes, 1989. 
[6] Las Casas, Bartolomé de. Brevíssima relação da destruição das Indias Ocidentais [1552]. Trad. Heraldo Barbuy. 2 ed. Porto Alegre: L\&PM, 1984.
Aos 34 anos, após uma formação praticamente de autodidata (Sarmiento só cursou de forma regular a escola primária) tornar-se-á grande educador, áspero polemista, político hábil e publicitário. Dominará a escrita e será capaz de compor descrições detalhadas da geografia do pampa argentino, com olhar detido em toda espécie de árvore, flor ou aroma; saberá elaborar uma tipologia social do gaúcho, de sua rotina no pampa, tão eficaz e pertinente, que o transformará de imediato e de maneira simultânea em referente para o pensamento histórico sobre o país e pedra de toque para a imaginação de toda uma linhagem literária argentina. Ainda no mesmo livro, interpreta a história do país desde sua independência em 1810 até 1845 , período dentro do qual delineará a biografia circunstanciada do terrível caudilho Facundo Quiroga, salpicada de digressões, diatribes e ponderações e termina prognosticando um futuro argentino, uma vez superada a ditadura de Juan Manuel Rosas (o que só aconteceria em 1852). Tudo isso num livro só, pontuado ainda com iluminações de grande estrategista político, qualidade essa que levaria Sarmiento à presidência, em 1868.

O título bifronte - Facundo ou civilização e barbárie - que alude, de um lado, à biografia do caudilho, e, de outro, à dialética entre o que se entende por mundo civilizado e o que seentende por barbárie, já aponta na direção de uma obra plural. Entre outras coisas, trata-se também de um panfleto político, na tradição da Brevíssima relação da destruição das Indias Ocidentais de Bartolomé de Las Casas ${ }^{6}$. Encontramos no texto de Sarmiento, como no de Las Casas, um esquematismo antitético, muitos exageros e fórmulas simplificadoras e caricaturais em que a história se coloca como campo de batalha entre forças antagônicas lutando entre si. Só que não estamos aqui em presença do maniqueísmo sistemático com que o frade dominicano reduzia o conflito entre indígenas eespanhóis no século XVI, posicionando frente a frente pobres carneirinhos e lobos famintos. Sarmiento propõe-se detratare desmoralizar o ditador argentino, seu maior inimigo político: aquele que representa para ele a personificação do mal, do atraso, da impossibilidade do progresso e é signo da estagnação política. Só que para tanto idealiza um texto em que isso possa ser feito sem que as farpas sejam dirigidas de forma direta. A primeira biografia que escreveu, sobre o general Félix Aldao, poucos meses antes de começar a escrever Facundo, era já de certa forma germe deste livro e também do seu proceder: um meio lateral de apontar na direção de Rosas.

Mas a questão é que Rosas é muito interpelado, e ressurge o tempo todo ao longo das mais de quatrocentas páginas: como a sombra de tudo que se narra, é o alvo de tudo que se diz. Mediante um procedimento literário absolutamente magistral, a primeira frase do livro, "Sombra terrível de Facundo, vou evocar-te para que te ergas, sacu- 
dindo o pó ensanguentado que cobre tuas cinzas [...]", produz um duplo movimento: trazer das sombras da morte o caudilho da província de La Rioja para iluminar e vitalizar sua trajetória, e empurrar Juan Manuel Rosas para as sombras do texto, sem voz, mas sempre a "escutar", como um interlocutor fantasma, tudo quanto for dito. A ele são atribuídos desde o começo e de forma direta os epítetos mais terríveis: "falso", "coração gelado", "espírito calculista", "um Maquiavel”, "Tirano", "monstro", déspota”, "esfinge Argentina” (por covarde e sanguinário). A Rosas dirige-se também de forma direta o narrador no último capítulo ("Presente e porvir"), quando o "Eu" narrativo encara de modo frontal seu interlocutor mudo, invocando-o na segunda pessoa do singular: "Insensato! O que fizeste?" (p.422). Um dos grandes prodígios do livro é justamente ter criado uma situação absolutamente fictícia, mas por isso mesmo de uma força real impressionante, na qual o "Tigre de los Llanos" Facundo Quiroga (exemplo máximo da barbárie provinciana), tendo ficado atrás, morto e enterrado, deixa agora eles dois - Rosas e Sarmiento a se verem finalmente um diante do outro, como num duelo de titãs. No Prólogo à edição aqui resenhada, Ricardo Piglia trabalha justamente essa ideia.

Nas páginas finais, através do olhar do estrategista, Sarmiento calcula o paradoxo segundo o qual, graças à política do terror praticada pela ditadura de Rosas, o país está já finalmente centralizado em Buenos Aires: "Porém não se creia que Rosas não conseguiu fazer progredir a República que está despedaçando [...]. A ideia dos unitários está realizada; apenas o tirano está demais" (p. 418). O olhar do escritor que tudo sopesa permite-lhe capitalizar o período sinistro da ditadura como um tempo de aprendizado, de educação política e social para o povo argentino. Um desfecho otimista, esperançoso de quem, apesar da adversa realidade circundante, nunca esmoreceu nas suas convicções, de quem estava se armando para assumir um dia ele mesmo o poder político do país. Nesse momento final irá repetir doze vezes (!) sua arenga contra Rosas, agora usando a terceira pessoa do singular: "Porque ele, não tomou uma medida administrativa [...]. Porque ele perseguiu o nome europeu [...]. Porque ele destruiu os colégios [...]" (pp.427-430), e assim por diante.

A eficácia de todo esse esforço por desacreditar o inimigo ficaria provada pelas palavras que o mesmo Rosas teria declarado após a publicação do livro: "O livro do louco Sarmiento é o melhor que já se escreveu contra mim;é assim que se ataca, senhor; é assim que se ataca; o senhor verá que ninguém irá me defender tão bem"7.

Outra grande eficácia do livro reside na sua estrutura. Tendo sido expostas já na "Introdução" as diretrizes gerais que norteiam tanto o aparato ideológico de Sarmiento como seus pressupostos esque-
[7] Saldías, Adolfo. Historia de la confederación [1911]. Buenos Aires: Editora Universitaria, 1973, p. 193. Tradução livre. 
[8] Há edições do Facundo que de fato dividem o livro em três partes, como por exemplo, a edição espanhola organizada para a Editora Nacional de Madri, em 1975, por Luis Ortega Galindo.

[9] Piglia o compara a Flaubert, no Prólogo à edição aqui resenha$\mathrm{da}(\mathrm{p} \cdot 38)$. máticos sobre os processos históricos, a obra poderia correr o sério risco de se tornar uma longa e árdua estrada de redundâncias e de desenvolvimentos previsíveis. Isso está longe de acontecer graças à estrutura completamente heterogênea de suas partes. É possível pensar o livro em três grandes blocos ${ }^{8}$, muito diversos em natureza e tratamento narrativo.

Um primeiro bloco que compreenderia os quatro capítulos iniciais, dedicado à descrição dos contextos físico, social, racial, econômico, cultural e histórico que determinariam a índole dos indivíduos que ali habitam; um segundo - o mais longo - que reúne os nove capítulos seguintes, em torno da "vida e obra" de Juan Facundo Quiroga; e os dois últimos capítulos, de teor mais político e panfletário. A repisada questão da multiplicidade de gêneros que residem nesta obra, já pulsa nesta divisão que supõe três viradas abruptas nos pressupostos narrativos e compositivos, assim como mudanças de tom, de perspectiva e de ritmo.

A descrição que Sarmiento é capaz de fazer da imensidão argentina, de seus pampas, desertos e planícies é digna de poeta. A poesia de suas frases, para além da descrição justa e pormenorizada, permite que a própria geografia penetre na linguagem e se faça expressão da vida natural. Ele cria cenas hipotéticas de viajantes, de encontros com animais selvagens, com a onça perigosa, com o passarinho silvestre; sua palheta harmoniza cores, esboça nuanças com a sensibilidade do grande artista. Sarmiento é um escritor nato` num tempo feliz em que a escrita podia intervir no curso das coisas, e foi o que ele fez.

No primeiro capítulo, "Aspecto físico da República argentina e caracteres, hábitos eideias que engendra", destaca-se a comparação com aquilo que Sarmiento entende pelo "mundo árabe e asiático", atrasado, violento, supersticioso. Isso funcionará quase como um motivo recorrente ao longo do livro porque lhe serve para definir o que seja o mundo bárbaro (comparado também ao mundo tártaro). Ora os luares na planície extensa do pampa argentino se lhe afiguram como um espetáculo com "certa tintura asiática" (p. 77), ora "o caudilho argentino é um Maomé" (p.133), e assim por diante. Francisco Foot Hardman, no posfácio à edição que aqui resenhamos, aponta para as relações intertextuais mais profundas desses quatro primeiros capítulos com a obra explicitamente citada por Sarmiento, As Ruínas, ou meditações sobre as revoluções dos impérios (1721), do conde Volney. Muitas das alusões ao Oriente no deserto do pampa, a caracterização dos seus tipos, além da cena de abertura da Introdução, em que Sarmiento invoca a sombra de Facundo Quiroga, seriam empréstimos e colagens de Volney. Isso vem reafirmar a atitude geral do narrador em Sarmiento, leitor compulsivo, autodidata genial que aproveita materiais de fontes bibliográficas e testemunhais diversas para compor seus panoramas, cenas e tipos. De fato, e isto causa verdadeiro espanto, Sarmiento nunca tinha estado no pampa quando realizou 
essas descrições antológicas. Valeu-se de narrações de vaqueiros e de descrições feitas por combatentes da guerra civil. Ele só veio conhecer o espaço tão perfeitamente descrito sete anos depois, em 1852, redigindo boletins para o "Exército Grande" de Urquiza que derrubaria finalmente a ditadura de Rosas.

Com relação ao Oriente, seu conhecimento deve ter sido fruto de tudo que ele apanhava, no ar de seu tempo, da visão romântica e exótica, até as leituras explicitamente declaradas de Volney. A questão é que para ele, sem ter ainda estado no pampa e sem nunca ter ido ao Oriente, como afirma categoricamente e sem deixar que o leitor possa ter tempo de parar para duvidar, "há algo nas soledades argentinas que traz à memória as soledades asiáticas [...]" (p.77). Por outras palavras, para os propósitos de sua tese, é importante inventar esse mundo de barbárie (sedutor e abominável ao mesmo tempo) lançando mão de tudo que estiver disponível e, assim, poder construir a oposição com o mundo civilizado da cidade, de modos elegantes "à europeia", instruído e trabalhador, que ele propõe para o futuro da pátria.

O determinismo oriundo da leitura de A democracia na América de Tocqueville (mais uma das referências citadas explicitamente por Sarmiento), entre outros, pairava sobre as concepções sarmientinas da formação do caráter dos povos. Somente por meio do contato direto com as ideias e a cultura europeias inculcadas nas escolas primárias é que o povo argentino poderia superar sua condição atávica de atraso que lhe chegava por duas vias: a indígena bárbara e a espanhola retrógrada (e, portanto, também bárbara).

Ao longo desses quatro capítulos iniciais aparecem alguns dos mitos que marcam de forma profunda e indelével a literatura argentina: a violência e galhardia gauchescas e a ociosidade anticapitalista do mundo da campanha, entre outros. Como não pensar em Borges quando lemos trechos como o seguinte:

[...] é preciso ver essas caras cobertas de barba, esses semblantes graves e sérios, como os dos árabes asiáticos, parajulgaro compassivo desdém quelhes inspira a visão do homem sedentário das cidades, que pode ter lido muitos livros, mas que não sabe aterrorizar um touro bravio e dar-lhe morte; que não saberá prover-se de cavalo em campo aberto, a pé e sem auxílio de ninguém; que nunca deteve um tigre, recebendo-o com um punhal na mão e o poncho envolvido na outra para lhe meter na boca enquanto lhe traspassa o coração e odeixa estendido a seus pés (p.92).

Também exercita Sarmiento seus dotes de crítico literário, incursionando na interface da ficção com o ensaio: analisa $O$ último dos moicanos de Fenimore Cooper, aproximando-o de $A$ cativa de Echeverría, dois antecedentes na ficcionalização do binômio civilização/barbárie. 
Arrola poemas de poetas cultos e o cancioneiro popular. Seu narrador está a esta altura, juntamente com o seu leitor, embevecido pelo encanto deste mito da vida do gaúcho, bárbara e desprezível - que ele retrata, lembra, inventa - repleta de força vital e literária.

Em "Originalidade e caracteres argentinos" e "Associação: a pulperia", provavelmente as passagens mais romanescas do livro, elaboram-se os tipos e os temas gauchescos que se constituirão em mitos: o "rastreador", o "baqueano", o "gaucho mau", o "cantor", a faca e o cavalo. O narrador oscila, com a ambiguidade sedutora própria de todo grande narrador, entre a admiração e a indignação diante desse mundo, segundo ele "a cavalo" entre o século XII e o século XIX. O mistério do poder e da força que esses seres bárbaros possuem contradiz, o tempo todo, a proposta de crítica. O narrador cai na cilada do fascínio do enigma cifrado nesses gaúchos. São eles, seres que conhecem, que possuem um saber da realidade ao seu redor, o que os torna perfeitamente pertinentes dentro do contexto em que são concebidos: $O$ rastreador, uma espécie de farejador de rastos e sinais, pela dignidade e o respeito que provoca a seu redor; o baqueano, pelos seus conhecimentos de topografia indispensáveis em qualquer façanha militar; o gaúcho mau, "sem que esse epíteto o desfavoreça de todo", cujo mistério "voa por toda a vasta campanha"; e o cantor, que de certa forma, é uma soma dos demais e o poeta que os canta. Campo e cidade entram aqui num confronto complicado porque, para Sarmiento, a concepção de progresso (para ele a passagem do campo à cidade) passa fundamentalmente pela troca de hábitos culturais, sem que a base econômica da defasagem esteja colocada. Daí o andamento ambíguo, contraditório da escrita nessas passagens. Martín Fierro viria, décadas mais tarde, se erguer contra todo o preconceito com que Sarmiento imaginou esta tipologia popular, embora, lendo a contrapelo o poema de José Hernández, se revelem todos os débitos que ele tem com a sua matriz.

Outra das contradições interessantes nestes primeiros quatro capítulos é a concepção ambivalente que se tem da Espanha. Ora é a "renegada da Europa, posta entre o Mediterrâneo e o oceano, entre a idade Média e o século XIX", cujo problema poderia ser compreendido por meio do "minucioso exame da Espanha americana, assim como as ideias e moralidade dos pais podem ser rastreadas por meio da educação e dos hábitos dos filhos" (p. 53), Espanha essa que mais adianteé definida como a face europeia e culta da República argentina, em oposição à "bárbara, americana, quase indígena", na hora de sua independência, em 1810 (p. 135). Essa "maleabilidade" dos conceitos utilizados pelo narrador neste livro fantástico repete-se em mais de uma oportunidade e pauta um estilo que vem a ser, por isso mesmo e antes de tudo, uma obra de ficção cujo protagonista principal não será nem Facundo nem Rosas, mas o próprio Sarmiento. O narradoré 
uma das caras deste personagem que avança no seu relato, refletindo sobre o próprio fazer a cada passo: "Dou tanta importância a esses pormenores porque eles servirão para explicar [...]" (p.134) ou mais à frente: "Precisei repassar todo o caminho até aqui percorrido a fim de chegar ao ponto no qual nosso drama começa" (p. 137), entre outros muitos exemplos ao longo da narrativa. Dessa forma nos envolve, sentimo-nos incorporados como escutas no processo desse "Eu" poderoso e envolvente que é o personagem-narrador ${ }^{10}$.

Os novecapítulos seguintes sãodedicados àfigura de Facundo, desde o nascimento até sua morte, assassinado a mando de Rosas, em Barranca Yaco. Fugindo da forma tradicional da biografia (proeza inusitada se lembrarmos, sobretudo, que Sarmiento escreve na primeira metade do século XIX), o narrador começa este esboço biográfico do caudilho e líder montonero ${ }^{11}$ narrando uma cena digna do melhor filme de faroeste ${ }^{12}$, na qual Facundo Quiroga se defronta com uma onça feroz. A ideia explicitada por Sarmiento é que as anedotas do personagem o revelam por inteiro. Essa é também uma teoria da composição que Borges desenvolveria depois. Toda a longa sequência do esboço da figura de Facundo é prova cabal da mão de mestre. A descrição física atravessada por digressões e conclusões deterministas e por comparações exóticas confirma o aspecto demoníaco da personalidade do feroz caudilho; a forma como o biógrafo continua fugindo do esquema tradicional de chave hegeliana leva-o a entremear os dados da vida do montonero com uma análise aguda da situação política de cada uma das províncias argentinas e de cada capital após a independência. Seu exercícioé uma tentativa de compreensão do quadro geral que ali estava posto entre as províncias aliadas a Buenos Aires e as regiões em litígio, e dentro desse quadro (com direito a esquemas gráficos), ele irá acompanhar o desenvolvimento da "carreira" de batalhas e enfrentamentos de Facundo. A estratégia compositiva geral do livro repete-se aqui em cada caso particular, ou seja, o narrador leva seu leitor a sobrevoar pela geografia de cada localidade para ir adentrando em seus meandros e intrigas palacianas. De certa forma, sua tese, que concebe o campo e a cidade como compartimentos estanques, como dois polos antagônicos e em pugna, se desmancha pela própria mão de sua narrativa, que mostra as guerras intestinas que unitários e federalistas irão travar dentro e fora das cidades.

Os episódios mais macabros e cruéis das andanças de Facundo não serão poupados, mas pairará sempre sobre eles um tom de admiração diante de tamanha altivez e coragem. A cena de sua morte será descrita em minuciosos detalhes, enaltecendo-se essa coragem. Borges fará dela o seu poema "El general Quiroga va en coche al muere"13. Sarmiento também terminará seduzido pelo seu herói, "um homem superior [...] de reputação misteriosa", apesar do propósito central de demonstrar o seu caráter bárbaro e desgovernado.
[10] Ricardo Piglia explora de maneira engenhosa e fértil esse tema no Prólogo da edição aqui resenhada.

[11] Montoneras eram unidades militares de extração rural, lideradas por caudilhos regionais que lutavam contra as milícias governamentais.

[12] As ligações com o gênero norteamericano são evidentes na obra em mais de uma ocasião.

[13] Borges, Jorge Luis.Luna de enfrente [1925]. Em português em: Primeira poesia. Texto bilíngue. Trad. Josely Vianna Baptista. São Paulo: Companhia das Letras. 2007, pp.112-113. 
[14] Rosas havia enviado uma comissão ao Chile, solicitando a extradição de Sarmiento para seu julgamento na Argentina. O presidente Monttdenegou o pedido.
Cabe destacar ainda nesta segunda parte a deliciosa e desvairada passagem em que Sarmiento se espraia sobre a importância das cores e do vestuário. Por mais descabido que possa parecer para o leitor de hoje, esses dois elementos passam a ser também mais uma arma com a qual Sarmiento arremete contra a barbárie e contra Rosas. "Sabeis o que é o tom colorado? Eu tampouco o sei; mas vou juntar algumas reminiscências", diz ele. A corvermelha, o colorado, símbolo dos rosistas, passará então a ser demonizada à custa de um fantástico elenco de exemplos oriundos dos mais diversos contextos em que o rubro se ligaria ao crime, aos selvagens, à barbárie, ao absolutismo europeu etc. Sua obsessão o leva até a improvável constatação de que nas bandeiras dos países europeus cultos jamais predomina o colorado, enquanto Argel, Tunis, Mongol, Turquia, Marrocos, Japão, Sião etc. fazem flamejar a cor do mal. Contra essa cor maligna, resplandece "o azul-celeste e o branco; o céu transparente de um dia sereno e a luz nítida do disco do sol: a paz e a justiça para todos" (p.229). Já o vestuário, sua mobilidade, a moda, o uso do fraque, são privilégios de uma sociedade culta e civilizada, ao passo que "na Ásia, onde se vive sob governos como o de Rosas, desde Abraão o homem traja vestuário talar" (p. 232). Mais adiante, nos capítulos finais, denuncia a perseguição de Rosas ao fraque e "a todas as instituições que nos esforçamos por toda parte para copiar da Europa" (p.396) e a substituição que o ditador impõe por pantalonas largas e soltas e todas as formas de trajes nacionais. A passagem da barbárie para a civilização é, de fato, cultural e comportamental na visão de Sarmiento, que chega até afirmar que "o elemento principal de ordem e moralização com que a República Argentina hoje conta é a imigração europeia" (p.434).

Uma vez morto Facundo, resta um país unido em torno do ditador que ele concebe como o espelho de todas as características negativas do caudilho, esboçadas nos capítulos anteriores. O ataque torna-se mais direto nos últimos dois capítulos que são antecedidos por justificativas do narrador que intui que sua história deveria acabar onde acaba a vida de Facundo. Os dois capítulos finais precisam ser então justificados pelo narrador-personagem que, evidentemente, não consegue se deter sem antes arremeter contra quem na verdade havia precipitado a escrita do livro ${ }^{14}$. Ele explica então: "Como sua morte [a de Facundo] não põe fim à série de fatos que me propus coordenar, e para não deixá-la truncada e incompleta, preciso continuar um pouco mais adiante, no caminho que sigo [...]" (p.36o), e antes do último capítulo, declara admitir que apesar de ter concluído seu ensaio sobre a vida do caudilho, precisa agora apreciar suas conseqüências e resultados "ora, favoráveis, ora adversos" (p.398). Nessa última parte, portanto, além de desprestigiar o tirano, o narrador se lançará na proposta de um futuro programa de reestruturação nacional para quando o ditador for derrocado. 
Este livro, queé muitos livros ao mesmo tempo, dá-nos a sensação de um mergulho profundo na mentalidade do século XIX que sentimos gravitar na raiz da nossa mentalidade em vários sentidos. Como afirma Foot Hardman nas palavras do posfácio, muitos dos processos aludidos por Sarmiento no seu Facundo têm se feito presentes na historia da América Latina contemporânea, ao longo das muitas décadas que nos separam das dele. Assim como encontramos também em escritores como Jorge Luis Borges, Ricardo Piglia, César Aira, Juan José Saer e Andrés Rivera (para citar apenas alguns) a reelaboração de seus personagens gaúchos, caudilhos, déspotas, intelectuais e escritores.

Para terminar estas notas, é preciso dizer que com a edição brasileira que ora temos em mãos estamos diante de um trabalho de tradução da mais alta qualidade que deve ser elogiado pela escolha do respeito à forma culta utilizada por Sarmiento neste livro, sem por isso ter se tornado esforço árduo para o leitor, muito pelo contrário. É interessante consignar a este respeito, que em carta dirigida por Sarmiento a Matías Calandrelli (autor de um dicionário etimológico da língua castelhana), em 1881, ele ratifica sua utilização de locuções antiquadas e castiças e invoca como razão principal o fato de ele ter sido criado, sem estudos regulares, em uma região afastada como era a província de San Juan, recebendo assim a língua dos conquistadores conservada sem alterações sensíveis. Mais uma contradição sarmientina, se pensarmos em seus abertos ataques às posturas conservadoras de Andrés Bello - travados no Chile por aqueles anos - com relação à grafia eà pronúncia da língua espanhola na América.

O critério do tradutor de conservar no original certas locuções platinas com o apoio de notas elucidativas é também muito feliz, já que permite ao leitor brasileiro adentrar de modo mais contundente o universo do pampa ali retratado. Também é necessário ressaltar que as notas que acompanham a leitura do texto refletem um esforço sério e exaustivo de pesquisa em fontes diversas e edições anotadas que resulta hoje indispensável para a completa compreensão do seu conteúdo histórico e contingente.Aedição reproduz também um mapa de 1930 que permite acompanhar o traçado dos múltiplos caminhos percorridos pela trama através da geografia argentina. Só ficaria a sugestão de incluir numa próxima edição um subtítulo diferente para cada um dos quatro capítulos que levam aqui somente o nome de "Guerra Social", já que cada um deles focaliza conflitos em lugares específicos: La Tablada, Oncativo, Chacón e Ciudadela, respectivamente. 